\section{BRAZIULIAN JOURNAL}

OF MEDICAL AND BIOLOGICAL RESFARCH

www.bjournal.com.br
ISSN 0100-879X

Volume 43 (8) 698-811 August 2010

BIOMEDICAL SCIENCES

AND

CLINICAL INVESTIGATION

Braz J Med Biol Res, August 2010, Volume 43(8) 806-811

doi: 10.1590/S0100-879X2010007500063

Evaluation of piroxicam- $\beta$-cyclodextrin as a preemptive analgesic in functional endoscopic sinus surgery

G.T. Keleş, I. Topcu, Z. Ekici and A. Yentür

The Brazilian Journal of Medical and Biological Research is partially financed by
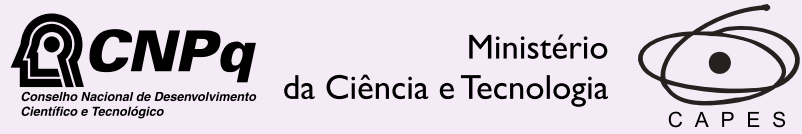

Ministério da Educação

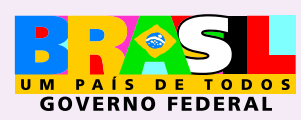

DTAPESP

Institutional Sponsors
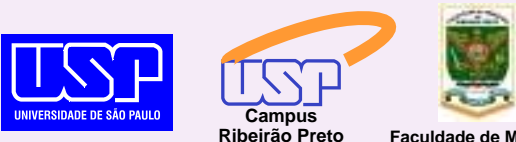

Ф SHIMADZU

GE Healthcare
Hotsite of proteomics metabolomics developped by: 


\title{
Evaluation of piroxicam- $\beta$-cyclodextrin as a preemptive analgesic in functional endoscopic sinus surgery
}

\author{
G.T. Keleş, I. Topçu, Z. Ekici and A. Yentür \\ Department of Anesthesiology and Reanimation, Celal Bayar University, Faculty of Medicine, Manisa, Turkey
}

\begin{abstract}
The preemptive analgesic efficacy and adverse effects of preoperatively administered piroxicam- $\beta$-cyclodextrin for post-endoscopic sinus surgery pain was determined in a prospective, double-blind, randomized, clinical study. Seventy-five American Society of Anesthesiologists status I-II patients, aged 18-65 years, were divided into three groups with similar demographic characteristics: group 1 received $20 \mathrm{mg}$ piroxicam- $\beta$-cyclodextrin, group 2 received $40 \mathrm{mg}$ piroxicam- $\beta$-cyclodextrin and group 3 received placebo orally before induction of general anesthesia. A blinded observer recorded the incidence and severity of pain at admission to the post-anesthesia care unit (PACU), at 15, 30, and $45 \mathrm{~min}$ in the PACU, and 1, 2, 4, 6, and $24 \mathrm{~h}$ postoperatively. All patients received patient-controlled morphine analgesia during the postoperative period and consumption was recorded for 24 h. During the PACU period, mean visual analogue scale values were significantly lower in groups 1 and 2 compared to group 3 ( $P<0.05)$. During the postoperative period, morphine consumption was $3.03 \pm 2.54,2.7 \pm 2.8$, and $5.56 \pm 3.12 \mathrm{mg}$ for each group, respectively $(P<0.05)$. As a side effect, bleeding was observed in groups 1 and 3 , nausea and vomiting in all groups, and edema only in group 3. However, no significant differences were detected in any of the parameters analyzed, which also included epigastric pain, constipation/diarrhea and headache. Similar hematological test results were obtained for all groups. Preemptive administration of piroxicam- $\beta$-cyclodextrin effectively reduced analgesic consumption, and $40 \mathrm{mg}$ of the drug was more effective than $20 \mathrm{mg}$ piroxicam- $\beta$-cyclodextrin without side effects during the postoperative period.
\end{abstract}

Key words: Analgesia; Piroxicam- $\beta$-cyclodextrin; Preemptive analgesia; Endoscopic sinus surgery

\section{Introduction}

Functional endoscopic sinus surgery (FESS) is a standard procedure for the treatment of chronic sinusitis. This procedure is assumed to be more comfortable and less painful for patients. Nonetheless, it is associated with mild to moderate postoperative pain, which is related to both surgical and nasal packing (1).

When the expected postoperative pain ranges from mild to moderate, routine analgesic treatment is usually based on non-opioid analgesics with rescue opioids (2). However, there is no consensus concerning the optimal analgesic regimen after endoscopic nasal surgery and an opioid-oriented treatment is still often used (3).

Non-steroidal anti-inflammatory drugs (NSAIDs) have a well-documented effect on acute postoperative pain (4). NSAIDs may be given preemptively or at the end of surgery (5). In adults, some studies report significantly better analgesia with NSAIDs administered before surgery $(6,7)$.
Piroxicam, a non-selective inhibitor of cyclooxygenase, belongs to a large group of NSAIDs and analgesic drug. Piroxicam is well absorbed within 30 min after oral administration. It is very effective for the treatment of pain of different characteristics and of inflammatory processes at a recommended dose regimen of $20 \mathrm{mg}$ once a day or 10 $\mathrm{mg}$ twice a day (8). Moreover, piroxicam at $40 \mathrm{mg} / \mathrm{day}$ has been shown to be very effective in the treatment of acute pain (9). Piroxicam- $\beta$-cyclodextrin (PBCD) is the first NSAID in which the active substance is complexed within the cyclic oligosaccharide, cyclodextrin (10). Since piroxicam is immediately bioavailable in this formulation, the onset of action is similar to that of a parenteral drug. The absorption rate of PBCD (5/h) was faster than that of piroxicam $(1.41 / \mathrm{h})$. Pain relief was found to increase with drug concentration in a hypothetical effect compartment. PBCD demonstrated an advantage with an onset of pain relief being obtained

Correspondence: G.T. Keleş, Department of Anesthesiology and Reanimation, Celal Bayar University, Faculty of Medicine, Manisa, Turkey. Fax:+90-236-237-0213. E-mail: gtezkeles@yahoo.com or gonul.keles@bayar.edu.tr

Received December 31, 2009. Accepted June 29, 2010. Available online July 8, 2010. Published August $13,2010$. 
$1 \mathrm{~h}$ earlier than with piroxicam alone (10).

The aim of the present prospective study was to compare the efficacy and adverse effects of 20 or $40 \mathrm{mg}$ PBCD preoperatively administered for the treatment of postoperative pain to adult patients following endoscopic sinus surgery.

\section{Patients and Methods}

The study was approved by the local Ethics Committee (Ref. No. 207) and patients gave written informed consent to participate. Seventy-five patients of both genders aged 18-65 years meeting physical status I or II of the American Society of Anesthesiologists (ASA) and undergoing endoscopic sinus surgery were allocated to receive $P B C D$ (Cycladol $^{\circledR}$, Abdi lbrahim, Turkey): 20 mg PBCD (group 1, $\mathrm{N}=25$ ), $40 \mathrm{mg}$ PBCD (group 2, $\mathrm{N}=25$ ) or placebo with a vitamin complex (group $3, \mathrm{~N}=25$ ). The randomization list was prepared using a computer-generated sequence of random numbers immediately before induction of anesthesia.

Patients who were unable to cooperate, who had a history of gastric bleeding, impaired liver and/or renal function, a history of drug or alcohol abuse, chronic pain requiring major analgesics, sedatives, or corticosteroids, or who had a known allergy to NSAIDs or other drugs used in the study were excluded. The type of surgery, anesthetic induction and management were standardized. After application of routine noninvasive monitors, such as ECG, NIBP, $\mathrm{SpO}_{2}$ (Datex-Ohmeda-GE), an intravenous (iv) cannula (18G Mediflon-Eastern Medikit Ltd., India) was inserted.

No premedication or prophylactic antiemetic drugs were given. All patients received anesthesia with $2-2.5 \mathrm{mg} / \mathrm{kg}$ propofol and $1 \mu \mathrm{g} / \mathrm{kg}$ remifentanyl. Muscle relaxation with $0.1 \mathrm{mg} / \mathrm{kg}$ vecuronium was given to facilitate tracheal intubation and mechanical ventilation. Standard monitoring was used, including electrocardiography (Lead II), heart rate, noninvasive arterial blood pressure, and pulse oximetry. The attending anesthesiologist managing intraoperative anesthesia was blinded to patient grouping. Anesthesia was maintained with $1.5-2 \%$ sevoflurane, remifentanyl infusion and $65 \%$ nitrous oxide in oxygen. The same surgeon performed all the surgical procedures using a standard surgical technique.

At the end of surgery, all anesthetics were discontinued, the patients were extubated after recovery of adequate spontaneous ventilation, and transferred to the post-anesthesia care unit (PACU).

An independent blinded observer recorded the degree of pain at PACU admission and at 15, 30, and 45 min in the PACU, and then at 1, 2, 4, 6, and $24 \mathrm{~h}$ after PACU in the ear, nose and throat (ENT) surgery department. In the PACU, all patients received morphine via an iv patient-controlled analgesia (PCA) pump (Pain Management Provider; Abbott, USA) with the following initial parameters: $1.0 \mathrm{mg} / \mathrm{mL}$ prepared; basal rate, 0; bolus, $1.0 \mathrm{mg}$ per time; lockout period, $5 \mathrm{~min}$. PCA continued during the $24 \mathrm{~h}$ after surgery. The degree of pain was measured using a $10-\mathrm{cm}$ visual analogue scale (VAS, where " 0 " is no pain and " 10 " the worst imaginable pain). In case of inadequate pain relief (VAS $\geq 4 \mathrm{~cm}$ ), rescue iv analgesia was given with $1 \mathrm{mg}$ bolus of morphine injected at 5-min intervals until adequate pain relief was achieved, and morphine consumption during the $24 \mathrm{~h}$ after surgery was recorded. Total morphine consumption and demand/delivery ratio per patient during the $24-\mathrm{h}$ period were recorded in all groups and compared. Demand/delivery ratio was defined as the number of analgesic requests made by the patients and the number of those requests, which resulted in successful deliveries.

Hematological tests (prothrombin time (PT) and active partial thromboplastin time (aPTT), were evaluated during the preoperative and postoperative periods. Nausea/ vomiting and other adverse effects (epigastric pain, edema, headache, bleeding, and sleep disorders) were also assessed during the 24-h postoperative period.

\section{Statistical analysis}

Demographic data, duration of anesthesia and duration of surgery of the groups were compared by the Student $t$-test. Total additional analgesic consumption and pain scores (VAS) were analyzed by the Mann-Whitney U-test. Nominal data (ASA, gender, the need for "rescue" analgesics, and incidence of side effects) were compared between groups using the chi-square or the Fisher exact test. Data are reported as means \pm SD, median values (25\%-75\%), and numbers $(\mathrm{N})$. A $P$ value of $<0.05$ was considered to be significant.

\section{Results}

The study involved 75 patients, with 25 patients in each treatment and placebo group. No patient was excluded from the study for any reason, and the drug was well tolerated. No differences in demographic parameters were observed between the three groups (Table 1).

Morphine consumption and demand for supplementary analgesia in the preemptive groups were significantly lower than that in the control group $(P<0.05)$, i.e., $3.03 \pm 2.54$ $\mathrm{mg}$ in group 1 and $2.7 \pm 2.8 \mathrm{mg}$ in group 2 vs $5.56 \pm 3.12$ $\mathrm{mg}$ in group $3(\mathrm{P}<0.05)$. The bolus/demand ratio $(\%)$ for group $2(43.1 \pm 25.7 \%)$ was significantly lower than that for group $1(62.9 \pm 19.2 \%)$ and group $3(78.1 \pm 23.5 \%)$ during the 24-h PCA period ( $P<0.05$; Table 2$)$.

Table 3 shows the incidence of side effects and the hematological tests for the three groups. Side effects were not related to the need for doses of morphine, and bleeding was controlled simply by changing nasal cavity packing without the need for surgical intervention. Sixteen percent of the patients in group 3 bled in the ENT surgery department period compared with $8 \%$ of the patients in group 1. Eight percent of the patients in group 3 had edema compared 
with $0 \%$ in groups 1 and 2 . Twenty percent of the patients in group 3 had nausea and vomiting compared with $16 \%$ of the patients in group 1 and in group 2. Nevertheless, the differences between groups for incidence of side effects and hematological parameters, such as PT and aPTT, were not statistically significant (Table 3).

Figure 1 shows mean VAS changes during the postoperative period in the three groups. During the PACU period, VAS values were 1 in groups 1 and 2, and 6 in group 3 only in the first 45 min of the PACU period $(P<$ 0.05). After the PACU period, VAS values were lower in groups 1 and 2 than in group 3 without significant differences during the 24-h recovery period (Figure 1).

\section{Discussion}

No reports were identified in the literature in PubMed, from 1990 to 2009, on the use of PBCD for postoperative analgesia after endoscopic sinus surgery, although it has been shown to be effective in reducing pain in other situations (11-18). NSAIDs are gaining popularity in the management of pain associated with ambulatory surgery. PBCD was regarded as an effective analgesic at doses of 20 and $40 \mathrm{mg} /$ day. Preemptive administration of PBCD effectively reduced morphine consumption, and especially the 40-mg dose was found to be more effective than the 20-mg dose and than the treatment administered to the control group during the postoperative period (11-18).

Surgical trauma generates powerful nociceptive impulses by the procedure itself and by the action of proteolytic and inflammatory agents that are released following tissue injury. This release of inflammatory mediators may result in pain for several hours.

The analgesic action of NSAIDs has been explained on the basis of their inhibition of the enzymes that synthesize prostaglandins. However, it is clear that NSAIDs exert their analgesic effect not only through peripheral inhibition of prostaglandin synthesis but also through a variety of other peripheral and central mechanisms. It is now known that there are two structurally distinct forms of the cyclooxygenase enzyme (COX-1 and COX2). COX-1 is a constitutive member of normal cells and COX-2 is induced in inflammatory cells. Inhibition of COX-2 activity represents
Table 1. Demographic data of the patients included in the study.

\begin{tabular}{lccc}
\hline & $\begin{array}{c}\text { Group 1 } \\
(20 \mathrm{mg} \mathrm{PBCD})\end{array}$ & $\begin{array}{c}\text { Group 2 } \\
(40 \mathrm{mg} \text { PBCD })\end{array}$ & $\begin{array}{c}\text { Group 3 } \\
\text { (placebo) }\end{array}$ \\
\hline Age (years) & $33.9 \pm 14.0$ & $39.5 \pm 14.6$ & $34.9 \pm 15.8$ \\
Gender (male/female) & $16 / 9$ & $17 / 8$ & $18 / 7$ \\
Weight (kg) & $67.6 \pm 13.0$ & $72.4 \pm 9.3$ & $71.2 \pm 16.2$ \\
ASA I/II & $20 / 5$ & $21 / 4$ & $23 / 2$ \\
Surgery duration (min) & $142.2 \pm 84.5$ & $136.8 \pm 60.6$ & $159.6 \pm 113.2$ \\
Anesthesia time (min) & $156.6 \pm 84.5$ & $154.4 \pm 62.3$ & $179.6 \pm 123.8$ \\
PACU period (min) & $34.2 \pm 6.6$ & $35.2 \pm 7.7$ & $33.0 \pm 3.1$ \\
\hline
\end{tabular}

Data are reported as means \pm SD or number for 25 patients in each group. $\mathrm{PBCD}=$ piroxicam- $\beta$-cyclodextrin; ASA I/II = physical status I or II of the American Society of Anesthesiologists; PACU = post-anesthesia care unit.

Table 2. Patient control analgesia characteristics.

\begin{tabular}{lccc}
\hline & $\begin{array}{c}\text { Group 1 } \\
(20 \mathrm{mg} \text { PBCD })\end{array}$ & $\begin{array}{c}\text { Group 2 } \\
(40 \mathrm{mg} \text { PBCD })\end{array}$ & $\begin{array}{c}\text { Group 3 } \\
\text { (placebo) }\end{array}$ \\
\hline Analgesic consumption (mg) & $3.03 \pm 2.54$ & $2.7 \pm 2.8$ & $5.56 \pm 3.12^{*}$ \\
PCA ratio (\%demand/delivery) & $62.9 \pm 19.2$ & $43.1 \pm 25.7^{\#}$ & $78.1 \pm 23.5$ \\
\hline
\end{tabular}

Data are reported as means \pm SD for 25 patients in each group. PBCD $=$ piroxicam- $\beta$-cyclodextrin; $\mathrm{PCA}$ ratio = patient control analgesia ratio (number of analgesic requests that resulted in successful deliveries). ${ }^{*} \mathrm{P}<0.05$, compared to groups 1 and 2. ${ }^{\mathrm{P}}<0.05$ compared to groups 1 and 3 (Mann-Whitney U-test).

Table 3. Summary of adverse effects and hematological tests in all groups.

\begin{tabular}{lccc}
\hline & $\begin{array}{c}\text { Group 1 } \\
(20 \mathrm{mg} \text { PBCD })\end{array}$ & $\begin{array}{c}\text { Group 2 } \\
(40 \mathrm{mg} \text { PBCD })\end{array}$ & $\begin{array}{c}\text { Group 3 } \\
\text { (placebo) }\end{array}$ \\
\hline Epigastric pain & - & - & - \\
Nausea/vomiting & $4(16)$ & $4(16)$ & $5(20)$ \\
Edema & - & - & $2(8)$ \\
Constipation/diarrhea & - & - & - \\
Headache & - & - & - \\
Bleeding & $2(8)$ & - & $4(16)$ \\
Sleep problems & - & - & - \\
PT (s) & $12.6 \pm 0.96$ & $12.66 \pm 1.31$ & $12.75 \pm 1.16$ \\
$\quad$ Preoperative & $13.33 \pm 1.46$ & $13.57 \pm 1.46$ & $14.45 \pm 3.4$ \\
$\quad$ Postoperative & & & \\
aPTT (s) & $28.03 \pm 2.3$ & $27.53 \pm 3.05$ & $29.35 \pm 4.22$ \\
$\quad$ Preoperative & $27.18 \pm 2.53$ & $27.12 \pm 2.87$ & $29.66 \pm 4.37$ \\
\hline Postoperative & & &
\end{tabular}

Data are reported as means \pm SD or number with percent in parentheses for 25 patients in each group. $\mathrm{PBCD}=$ piroxicam- $\beta$-cyclodextrin; $\mathrm{PT}=$ prothrombin time; aPTT = activated partial tromboplastin time. 


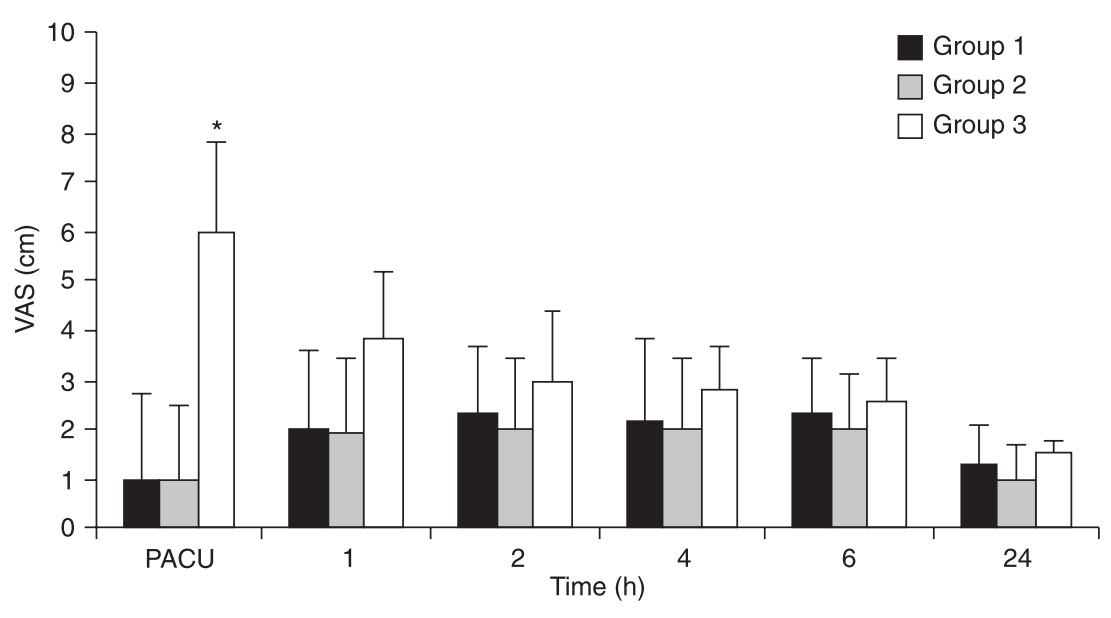

Figure 1. Intensity of postoperative pain determined by the visual analogue scale (VAS, " 0 " is no pain and " 10 " the worst imaginable pain). Data are reported as means \pm SD for 25 patients in each group. Post-anesthesia care unit (PACU) period included 15, 30 and 45 min after the operation in the operating theatre; 1, 2, 4, 6, and $24 \mathrm{~h}$ were in the ENT surgery department. ${ }^{*} \mathrm{P}<0.05$ compared to groups 1 and 2 according to VAS scores (Mann-Whitney U-test).

the most likely mechanism of action of NSAID-mediated analgesia, while the ratio of inhibition of COX-1 to COX-2 by NSAIDs should determine the likelihood of adverse effects. There is increasing evidence that NSAIDs have a central mechanism of action that augments the peripheral mechanism. This effect may be the result of interference with the formation of prostaglandins within the central nervous system (19).

Moreover, laboratory and clinical studies $(20,21)$ have provided evidence that inhibition of COX-2 up-regulation at the spinal level is a key factor for preoperative NSAID efficacy. Piroxicam is a nonselective COX inhibitor. Therefore, the analgesic effect of NSAIDs might also depend on a central effect. Recent investigations have shown preemptive analgesia by NSAIDs to be effective $(6,7,22)$. In preemptive analgesia, selection of the drug and dose is very important.

Piroxicam, a potent NSAID, has low solubility in water and a long absorption time, reaching a maximum concentration within about $2 \mathrm{~h}$ (23). Free, non-complexed piroxicam has a longer half-life (30 to $60 \mathrm{~h}$ ) in healthy individuals than most of the other currently available NSAIDs, and requires administration only once daily. Piroxicam can be complexed with $\beta$-cyclodextrin, an inert cyclic oligosaccharide molecule, which is a non-reducing macro-ring formed

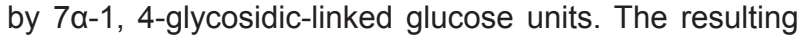
complex, PBCD, considerably increases the water solubility as well as the rate of dissociation of poorly soluble piroxicam, leading to a higher rate of gastrointestinal absorption than piroxicam. The absorption rate of PBCD has been demonstrated to be considerably faster than that of free piroxicam (24). Hence, peak blood concentrations of the drug are more rapidly achieved, and the analgesic peak also sets in earlier. Clinically, this results in an earlier onset of analgesia compared with im administration, generally within 30 min vs 2 to $4 \mathrm{~h}$ when compared to the standard formulation (25). Paolaggi and Lefrançois (26) suggested that the clinical advantages of PBCD were clearly demonstrated in an acute back pain model. Oral PBCD provided a rapid onset of analgesia and, more importantly, this rapid-onset effect was coupled with a longer duration of activity.

Although FESS is now among the most common head and neck surgical procedures, there have been very few studies of the subsequent levels of pain. However, information on the severity and duration of the pain that a patient can expect to experience after FESS is of great importance. It can enable better patient counseling, allowing patients to be more prepared for the postoperative experience and possibly improving the outcome. In fact, the severity of expected pain may be the deciding factor for many patients on whether to proceed with FESS or to suffer their existing pain due to nasal or sinus disease.

Pain after nasal and sinus surgery is usually maximal in the first $24 \mathrm{~h}$. During this time, patients usually take narcotic analgesics for symptomatic relief. Morphine is the most widely used drug to control postoperative pain. Although morphine is effective, it is also associated with frequent adverse effects such as sedation, nausea, vomiting, urinary retention, pruritus, and respiratory depression. For this reason, commonly used protocols of postoperative analgesia are based on a multipharmacologic approach, which includes non-opioid analgesics in order to achieve a morphine-sparing effect with a concomitant reduction in morphine-related adverse effects. NSAIDs and, more recently, selective or non-selective COX-2 inhibitors are among the most commonly used non-opioid analgesics for such a purpose (27). The present study was based on the hypothesis that oral PBCD as preemptive analgesia would reduce the severity of a patient's pain in the first 24 $h$ after FESS and thereby diminish the amount of narcotics consumed. Furthermore, we believed that by interrupting the pain early, the patient's overall pain perception/anxiety state would be diminished and that improved pain control in the first 6 postoperative hours would have a carryover effect on the ensuing period.

In comparative trials, PBCD acted more rapidly and provided greater pain relief than piroxicam (26) or etodolac (28). Patients treated with PBCD required a shorter treat- 
ment period for the pain to disappear in comparison with patients treated with other NSAID, supporting the hypothesis that pain may be self-limiting provided that the initial acute painful phase is rapidly and effectively treated (29). A meta-analysis demonstrated that a single oral dose of piroxicam (20-40 mg) had a similar efficacy as intramuscular morphine $(10 \mathrm{mg})$ in patients with moderate to severe postoperative pain (30).

The analgesic effects of rofecoxib and hydrocodone/ acetaminophen have been evaluated in FESS. Previous studies have demonstrated decreased postoperative narcotic requirement in patients undergoing ambulatory surgery who were treated with NSAIDs preoperatively $(5,30)$. Cepeda et al. (31) reported a significant reduction in morphine consumption and opioid-related side effects in the early postoperative period by adding iv ketorolac to an opioid-based analgesia. Similarly, Turan et al. (5) reported that preoperative oral administration of rofecoxib provided a significant analgesic benefit and reduced the need for rescue opioids in patients undergoing nasal septal and

\section{References}

1. Leykin Y, Casati A, Rapotec A, Dalsasso M, Barzan L, Fanelli $\mathrm{G}$, et al. Comparison of parecoxib and proparacetamol in endoscopic nasal surgery patients. Yonsei Med J 2008; 49: 383-388.

2. Dolin SJ, Cashman JN, Bland JM. Effectiveness of acute postoperative pain management: I. Evidence from published data. Br J Anaesth 2002; 89: 409-423.

3. Church CA, Stewart C, Lee TJ, Wallace D. Rofecoxib versus hydrocodone/acetaminophen for postoperative analgesia in functional endoscopic sinus surgery. Laryngoscope 2006; 116: 602-606.

4. Kokki H. Nonsteroidal anti-inflammatory drugs for postoperative pain: a focus on children. Paediatr Drugs 2003; 5: 103-123.

5. Turan A, Emet S, Karamanlioglu B, Memis D, Turan N, Pamukcu Z. Analgesic effects of rofecoxib in ear-nose-throat surgery. Anesth Analg 2002; 95: 1308-1311.

6. Trampitsch E, Pipam W, Moertl M, Sadjak A, Dorn C, Sittl $\mathrm{R}$, et al. [Preemptive randomized, double-blind study with lornoxicam in gynecological surgery]. Schmerz 2003; 17: 4-10.

7. Priya V, Divatia JV, Sareen R, Upadhye S. Efficacy of intravenous ketoprofen for pre-emptive analgesia. J Postgrad Med 2002; 48: 109-112.

8. Lee CR, Balfour JA. Piroxicam-beta-cyclodextrin. A review of its pharmacodynamic and pharmacokinetic properties, and therapeutic potential in rheumatic diseases and pain states. Drugs 1994; 48: 907-929.

9. Sliva J. Piroxicamum. Remedia 2004; 14: 398-405.

10. Pijak MR, Turcani P, Turcaniova Z, Buran I, Gogolak I, Mihal A, et al. Efficacy and tolerability of piroxicam-betacyclodextrin in the outpatient management of chronic back pain. Bratisl Lek Listy 2002; 103: 467-472.

11. Chang ST, Chen LC, Chang CC, Chu HY, Tsai KC. Effects sinus surgery. Our results are consistent with these reports. In our study, significantly decreased narcotic requirements were shown in endoscopic sinus surgery patients treated preoperatively with oral PBCD. We found a single dose of $40 \mathrm{mg} \mathrm{PBCD}$ to be effective for $24 \mathrm{~h}$, and this was safe and comfortable when compared with $20 \mathrm{mg}$ and placebo.

Reported adverse effects associated with the preoperative use of NSAIDs include headache, nausea, vomiting, dizziness, bleeding, and gastric pain. In our study, most of the participants reported no adverse effects. The anticipated gastrointestinal and neurologic adverse effects were not seen in the study groups. No adverse problems were encountered with the preoperative administration of $40 \mathrm{mg}$ PBCD.

Endoscopic sinus surgery is associated with moderate pain right after surgery that can be prevented by using NSAIDs. Oral preemptive analgesia with $40 \mathrm{mg}$ PBCD is a simple procedure, which decreases postoperative pain and the need for analgesic rescue medication after functional endoscopic sinus surgery. of piroxicam-beta-cyclodextrin sachets on abnormal postural sway in patients with chronic low back pain. J Clin Pharm Ther 2008; 33: 495-506.

12. Bannwart B, Bertin P, Pehourcq F, Schaeverbeke T, Gillet $P$, Lefrancois G, et al. Piroxicam concentrations in plasma and synovial fluid after a single dose of piroxicam-betacyclodextrin. Int J Clin Pharmacol Ther 2001; 39: 33-36.

13. Sjaastad O, Antonaci F. A piroxicam derivative partly effective in chronic paroxysmal hemicrania and hemicrania continua. Headache 1995; 35: 549-550.

14. Dolci G, Ripari M, Pacifici L, Umile A. Evaluation of piroxicam-beta-cyclodextrin, piroxicam, paracetamol and placebo in post-operative oral surgery pain. Int J Clin Pharmacol Res 1994; 14: 185-191.

15. Serni U. Rheumatic diseases - clinical experience with piroxicam-beta-cyclodextrin. Eur J Rheumatol Inflamm 1993; 12: 47-54.

16. Reginster JY, Franchimont P. Piroxicam-beta-cyclodextrin in the treatment of acute pain of rheumatic disease. Eur $J$ Rheumatol Inflamm 1993; 12: 38-46.

17. Trucco M, Antonaci F, Sandrini G. Hemicrania continua: a case responsive to piroxicam-beta-cyclodextrin. Headache 1992; 32: 39-40.

18. Marcucci M, Panelli G, Cambini S. Clinical experience in the treatment of dental pain. Clin J Pain 1991; 7 (Suppl 1): S72-S76.

19. Cashman JN. The mechanisms of action of NSAIDs in analgesia. Drugs 1996; 52 (Suppl 5): 13-23.

20. Buvanendran A, Kroin JS, Tuman KJ, Lubenow TR, Elmofty $\mathrm{D}$, Moric $\mathrm{M}$, et al. Effects of perioperative administration of a selective cyclooxygenase 2 inhibitor on pain management and recovery of function after knee replacement: a randomized controlled trial. JAMA 2003; 290: 2411-2418.

21. Moiniche $S$, Kehlet $H$, Dahl JB. A qualitative and quantitative 
systematic review of preemptive analgesia for postoperative pain relief: the role of timing of analgesia. Anesthesiology 2002; 96: 725-741.

22. Kissin I. Preemptive analgesia. Anesthesiology 2000; 93: 1138-1143.

23. Acerbi D. Pharmacokinetic profile of piroxicam $\beta$-cyclodextrin. Drug Invest 1990; 2: 42-49.

24. Woodcock BG, Acerbi D, Merz PG, Rietbrock S, Rietbrock N. Supermolecular inclusion of piroxicam with beta-cyclodextrin: pharmacokinetic properties in man. Eur J Rheumatol Inflamm 1993; 12: 12-28.

25. Wang D, Miller R, Zheng J, Hu C. Comparative population pharmacokinetic-pharmacodynamic analysis for piroxicambeta-cyclodextrin and piroxicam. J Clin Pharmacol 2000; 40: 1257-1266.

26. Paolaggi JB, Lefrançois G. Therapeutic efficacy and tolerability of piroxicam- $\beta$-cyclodextrin in outpatient treatment of acute back pain. Lett Rhumatol 1995; 214: 1-7.
27. Leykin Y, Casati A, Rapotec A, Dal Sasso M, Barzan L, Fanelli $\mathrm{G}$, et al. A prospective, randomized, double-blind comparison between parecoxib and ketorolac for early postoperative analgesia following nasal surgery. Minerva Anestesiol 2008; 74: 475-479.

28. Davoli L, Ciotti G, Biondi M, Passeri M. Piroxicam- $\beta$ cyclodextrin in the treatment of low-back pain: controlled study vs. etodolac. Curr Ther Res 1989; 46: 940-947.

29. Smith D, McMurray N, Disler P. Early intervention for acute back injury: can we finally develop an evidence-based approach? Clin Rehabil 2002; 16: 1-11.

30. Edwards JE, Loke YK, Moore RA, McQuay HJ. Single dose piroxicam for acute postoperative pain. Cochrane Database Syst Rev 2000; CD002762.

31. Cepeda MS, Carr DB, Miranda N, Diaz A, Silva C, Morales O. Comparison of morphine, ketorolac, and their combination for postoperative pain: results from a large, randomized, double-blind trial. Anesthesiology 2005; 103: 1225-1232. 